\title{
Electrochemical behavior of spray deposited nickel oxide (NiO) thin film in Alkaline electrolyte
}

\author{
Bilal Brioual ${ }^{1 *}$, Zaid Rossi $^{1}$, Abdessamad Aouni ${ }^{1}$, Mustapha Diani ${ }^{1}$, Mohammed Addou ${ }^{1}$, and Mohammed Jbilou ${ }^{1}$ \\ ${ }^{1}$ Equipe de recherche en Couches Minces et Nanomatériaux (CMN), FST, Université Abdelmalek Essâadi, Tanger-Maroc, Morocco
}

\begin{abstract}
Nickel oxide (NiO) Thin film was successfully deposited on the glass substrate using an inexpensive spray pyrolysis (SP) technique. The structural, morphological, and optical properties have been studied, thus the electrochemical behavior of NiO film in Alkaline electrolytes has been investigated. The X-ray diffraction (XRD) analysis showed that $\mathrm{NiO}$ thin film exhibit a polycrystalline cubic rock-salt structure with a preferential orientation on the plane (111). This result was confirmed using Raman spectroscopy. The Scanning Electron Microscopy (SEM) images exhibit a smooth and dense surface without major cracks. Optical analysis shows an average transmission of about $55 \%$ in the visible light range, and the optical band gap energy was estimated by Tauc's method and showed a value of $3,71 \mathrm{eV}$. Electrochemical properties as specific capacitance (Csp), optical density variation $(\Delta \mathrm{OD})$, and Coloration efficiency (CE) were studied using cyclic voltammetry in $1 \mathrm{M} \mathrm{KOH}$ and $1 \mathrm{M} \mathrm{NaOH}$ electrolytes. The results indicated that the behavior of the $\mathrm{NiO}$ layer in $\mathrm{KOH}$ is more effective than in $\mathrm{NaOH}$ electrolytes.
\end{abstract}

\section{Introduction}

For several years, transition metal oxides have attracted a noticeable attention of researchers due to their promising characteristics for various application fields. Among these materials, nickel oxide (NiO) is an attractive material because of its good magnetic, thermal, optical, mechanical and, electrical performance [1], [2], [3]. The stoichiometric $\mathrm{NiO}$ crystal is an insulator, whereas the conductivity can be enhanced in pure $\mathrm{NiO}$ by creating $\mathrm{Ni}$ vacancies [4]. The most attractive properties of $\mathrm{NiO}$ are; low material cost, wide bandgap semiconductor (3.6-4.0 eV) [5], excellent electrochemical stability [6], and finally the possibility of synthesis by a variety of techniques [7].

$\mathrm{NiO}$ layers can be used in many applications, including photo-catalysts [8], optoelectronic devices [9], antiferromagnetic layers [10], solar cells [11], gas sensors [12], supercapacitors [13], and electrochromic devices [14]. In electrochemistry, $\mathrm{NiO}$ thin films can be used as Counter-electrode, which $\mathrm{WO}_{3}$ is the Work-electrode (WE) in electrochromic devices (ECDs) [15], due to its high coloration efficiency (CE), its fast switching between the decolored and colored states, its good cyclic reversibility and memory effect [16].

*Corresponding author: bilal.brioual@etu.uae.ac.ma
Various methods were used to prepare $\mathrm{NiO}$ thin layers, such as chemical vapor deposition (CVD) [17], atomic layer deposition (ALD) [18], dc-magnetron sputtering [19], pulsed laser deposition (PLD) [20], electron-beam evaporation [21], spray pyrolysis [22], sol-gel process [23], chemical bath deposition (CBD) [24] and the electrodeposition process etc. [1], [25]. Among these methods, the spray pyrolysis technique has many advantages; economical, easy to prepare and permits to control the deposition conditions without the need of high vacuum and offers the possibility for large area deposition [22].

In this work, a thin film of $\mathrm{NiO}$ was synthesized by the spray pyrolysis method. The structural, optical, and morphological properties of the $\mathrm{NiO}$ layer have been studied. Thus, the electrochemical behavior in Alkaline electrolytes has been demonstrated using cyclic voltammetry $(\mathrm{CV})$.

\section{Experimental procedure}

Before depositing the film, the glass substrates were cleaned chemically in Acetone, Ethanol, and dilute hydrochloric acid $(\mathrm{HCl})$ respectively for 15 minutes in each solution, separated by rinsing in distilled water. Then several tests were made to find the optimal conditions for the preparation of the specimen using the spray pyrolysis method. A detailed description of this technique has been explained in [26]. After the optimization of parameters, a $\mathrm{NiO}$ thin layer was deposited on an amorphous glass substrate preheated at $450^{\circ} \mathrm{C}$. This temperature was 
chosen during the optimization of the deposit parameters because, at other temperatures such as 350, 400 and 500, impurities have appeared in the thin films such as $\mathrm{H}_{2} \mathrm{O}$ and metallic nickel. $0,025 \mathrm{~mol} / 1$ of hexahydrate nickel chloride $\left(\mathrm{NiCl}_{2} \cdot 6 \mathrm{H}_{2} \mathrm{O}\right)$ was used as a precursor and dissolved in $50 \mathrm{ml}$ of distilled water. The deposit parameters are summarized in Table 1.

Table1. Deposition parameters of the spray pyrolysis

\begin{tabular}{|c|c|}
\multicolumn{2}{|c|}{ technique. } \\
\hline Parameters & Values \\
\hline Precursor concentration & $0,025 \mathrm{M}$ \\
\hline Solution flow rate & $1,5 \mathrm{ml} / \mathrm{min}$ \\
\hline Compressed air pressure & $0,5 \mathrm{bar}$ \\
\hline Spray time & 8 minutes \\
\hline $\begin{array}{c}\text { Substrate temperature } \\
\text { Nozzle-Substrate } \\
\text { distance }\end{array}$ & $450^{\circ} \mathrm{C}$ \\
\hline
\end{tabular}

\section{Characterization techniques}

X-ray diffraction analysis (XRD) was performed using a D8 ADVANCE X-ray diffractometer $(\lambda \mathrm{K} \alpha 1, \mathrm{Cu})$. To confirm the crystalline phase a micro-Raman spectroscopy SENTERRA II, with a laser source set at $532 \mathrm{~nm}$ was used. The SHIMADZU Ultraviolet-Visible Near Infrared (UV-Vis-NIR) spectrometer was adopted to inspect the optical properties. The morphological characteristics were explored by scanning electron microscopy (SEM), with an accelerated voltage at $10 \mathrm{kV}$, a magnification of $x 40 \mathrm{~K}$, and an emission current of 120 $\mu \mathrm{A}$.

For the electrochemical study, NiO thin film was deposited on Indium Tin Oxide (ITO) substrate. This film was immersed in two different electrolytic solutions. The first is $1 \mathrm{M} \mathrm{KOH}$ and the second is $1 \mathrm{M} \mathrm{NaOH}$. The cyclic voltammetry measurements were based on a three-contact electrode system; saturated calomel (SCE) as the reference, a platinum sheet as a back-contact electrode, and $\mathrm{NiO} / \mathrm{ITO}$ as the working electrode.

\section{Results and discussion}

\subsection{X-ray diffraction results}

The XRD diagram of the NiO layer deposited on a glass substrate is shown in Figure 1. The pattern shows a polycrystalline film with a cubic structure. The diffraction peaks observed at the $2 \theta$ diffraction angles $37,26^{\circ} ; 43,31^{\circ}$ and $79,36^{\circ}$ are attributed to the crystallographic planes (111), (200) and (222), respectively with a strong preferred orientation corresponding to the direction (111). Using the International Center for Diffraction Data (ICDD) card number (04-0835), these peaks are indexed in a cubic rock-salt structure. These results match other studies [27], [28].

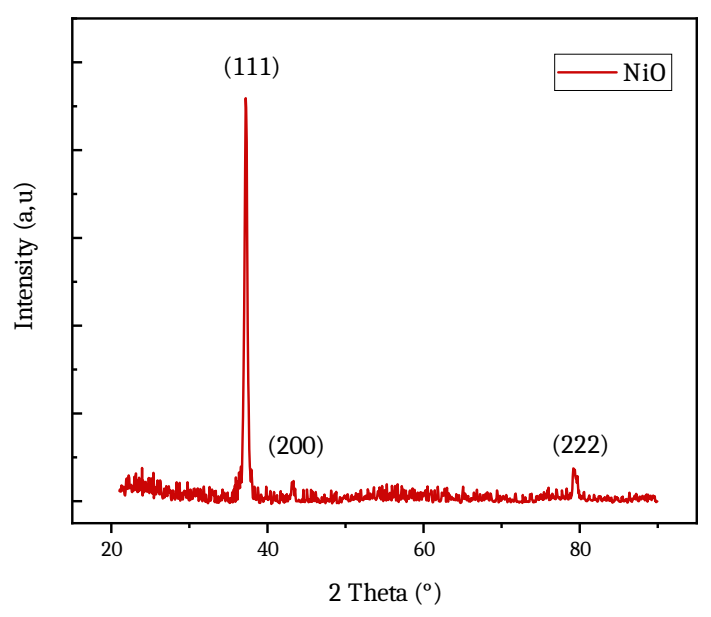

Figure 1. X-ray diffraction patterns of $\mathrm{NiO}$ film on the glass substrate.

The structural parameters of the sprayed thin film are listed in Table 2.

Table 2. Structural parameters of the elaborated sample.

\begin{tabular}{|l|c|l|l|l|l|}
\hline Film & $\begin{array}{c}2 \theta \\
\left({ }^{\circ}\right)\end{array}$ & $\mathrm{d}_{\mathrm{hkl}}(\AA)$ & $\mathrm{a}(\AA)$ & $\mathrm{D}(\mathrm{nm})$ & $\varepsilon(\%)$ \\
\hline $\mathrm{NiO}$ & 37,26 & 2,41 & 4,176 & 19,12 & 0,0018 \\
$(111)$ & & & & & \\
\hline
\end{tabular}

The average size of the crystallite $\left(\mathrm{D}_{\mathrm{hkl}}\right)$ corresponding to $\mathrm{NiO}$ is estimated from the XRD results using the Scherrer equation (Eq. (1)):

$$
D_{h k l}=\frac{0,9 \lambda}{\beta_{h k l} \cos \theta_{h k l}}
$$

Where $\theta_{\mathrm{hkl}}$ corresponds to Bragg's diffraction angle, $\lambda$ is the wavelength and $\beta_{\mathrm{hkl}}$ is the full width at Half-maximum intensity (FWHM) of the diffraction peak.

The lattice constant was determined using the cubic structure formula (Eq. (2)).

$$
a=\frac{d_{h k l}}{\sqrt{h^{2}+k^{2}+l^{2}}}
$$

Where hkl are the Miller indices and $d_{\mathrm{hkl}}$ represents the inter-plenary distance.

The strain $\varepsilon$ in the film can be estimated using the following equation (Eq. (3)).

$$
\varepsilon=\frac{\beta_{h k l} \cos \theta_{h k l}}{4}
$$




\subsection{Raman spectroscopy results}

Figure 2 shows the Raman spectra of the $\mathrm{NiO}$ thin film in the range from $60 \mathrm{~cm}^{-1}$ to $1600 \mathrm{~cm}^{-1}$. There are two prominent peaks around $550 \mathrm{~cm}^{-1}$ and $1100 \mathrm{~cm}^{-1}$, suggesting the one-phonon first-order and two-phonon second-order longitudinal-optical modes respectively [29]. These results confirm that the nanocrystalline $\mathrm{NiO}$ is successfully deposited.

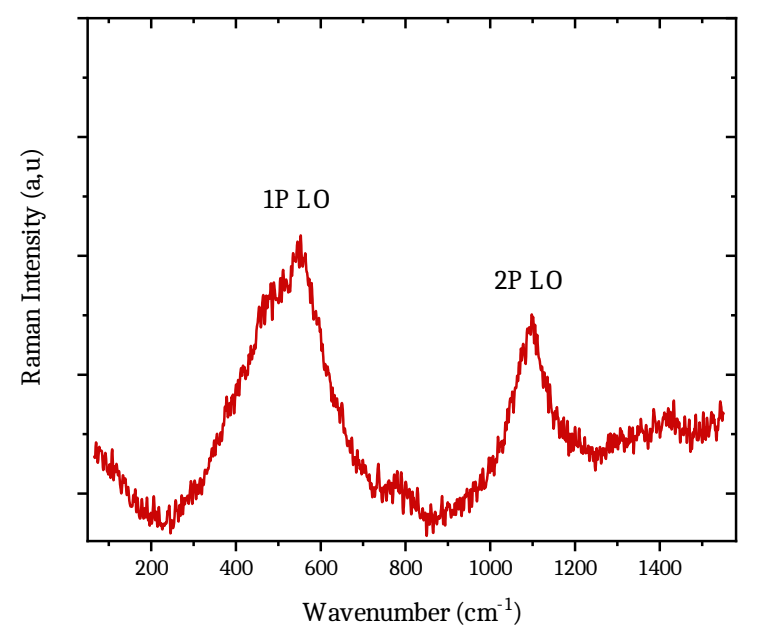

Figure 2. Raman spectra of $\mathrm{NiO}$ thin film.

\subsection{Morphology}

The surface morphology of the $\mathrm{NiO}$ layer was analyzed using The Scanning Electron Microscopy at different magnifications (7500 and 40.000 magnification). Figure 3 represents the morphological properties of the sprayed film on the glass substrate. The images of the NiO layer exhibit a smooth and dense surface suggesting a poor surface area of the film which is not helpful for a good electrochemical performance, However, the porous structure of the $\mathrm{NiO}$ layer provides a large reaction surface [30].

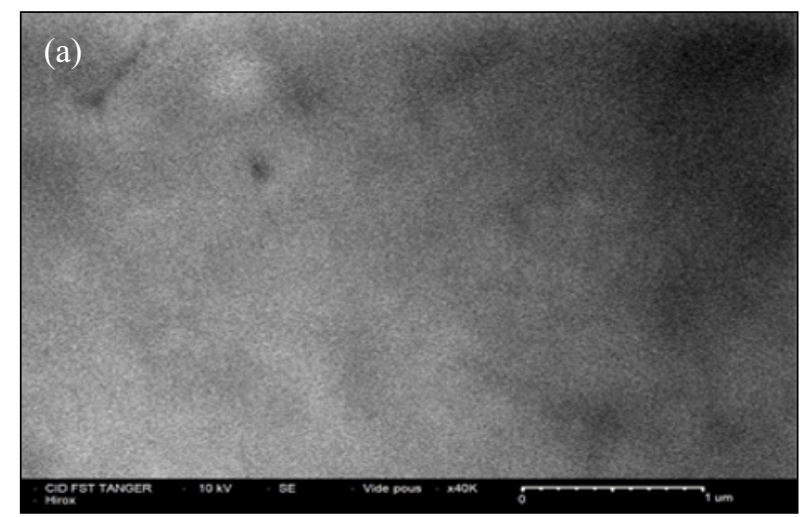

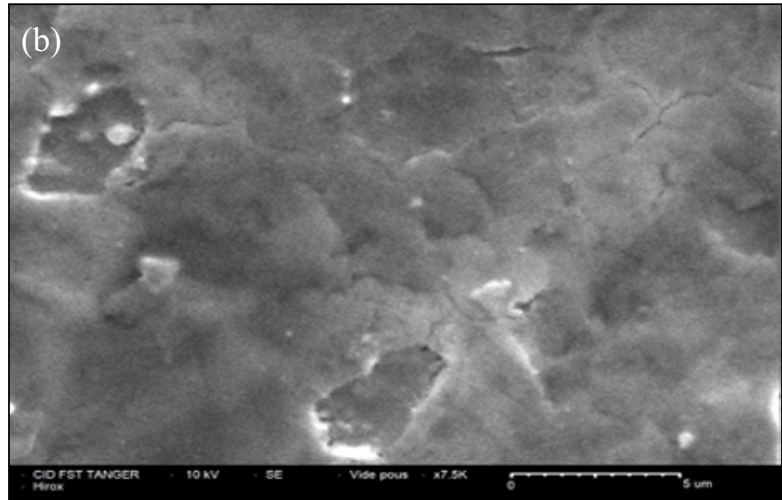

Figure 3. SEM images of the sprayed $\mathrm{NiO}$ film, (a) 40.000 magnification (b) 7500 magnification.

\subsection{Optical properties}

The measurement of optical spectrum for $\mathrm{NiO}$ thin film was carried out using a UV-VIS-NIR spectrometer. Figure 4 shows the transmission spectra of $\mathrm{NiO}$ thin film grown on the glass substrate in the $300-1500 \mathrm{~nm}$ wavelength range.

Figure. 4 indicates that the transmittance is increased from low wavelength to higher wavelength region and the average transmission is about $55 \%$ in the visible light range. This relatively low value of the transmission may be due to the technique used.

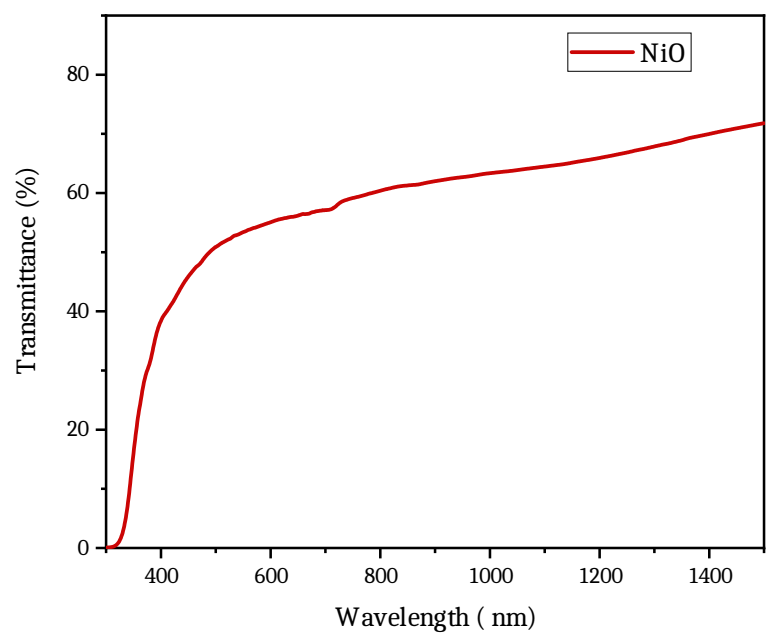

Figure 4. Transmittance spectra of $\mathrm{NiO}$ thin film.

The optical bandgap of the film was estimated using Tauc's equations:

$$
(\alpha \mathrm{h} v)=A(h v-E g)^{n}
$$

Where, Eg the optical bandgap energy, A is a constant, and $\mathrm{n}=2$ for direct bandgap. 
From the plots of $(\alpha h v)^{2}$ versus hv, Eg was calculated by extrapolating the linear portion of the curve to the energy axis for $(\alpha h v)^{2}=0$ (Figure 5).

The calculated energy bandgap value is $3,71 \mathrm{eV}$.

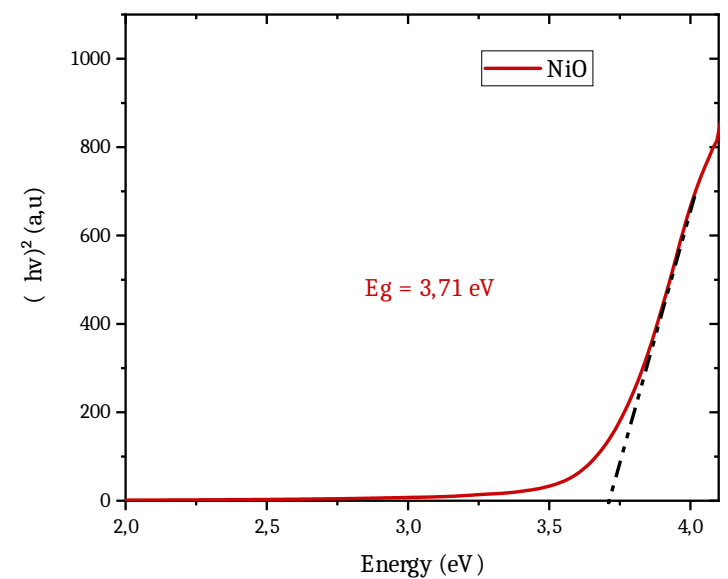

Figure 5. The $(\alpha h v)^{2}$ vs hv plots for NiO layer deposited on the glass substrate.

\subsection{Electrochemical measurements}

For the electrochemical study, a new sample is reprepared with the same conditions cited in the experimental details section except for the glass substrate which is replaced by ITO substrate to ensure the conductivity of the elaborated $\mathrm{NiO}$ thin film (NiO/ITO).

The electrochemical properties of spray deposited $\mathrm{NiO}$ thin film are investigated in two different electrolytes such as $1 \mathrm{M} \mathrm{KOH}$ and $1 \mathrm{M} \mathrm{NaOH}$ by cyclic voltammetry. The measurement is investigated in the three-electrode system, consisting of $\mathrm{NiO} / \mathrm{ITO}$ working electrode, Standard calomel electrode (SCE) reference electrode, and platinum $(\mathrm{Pt})$ counter-electrode.

Figure 6 (a) and (b) show CV curves at different scan rates $(5,10$, and $20 \mathrm{mv} / \mathrm{s})$ of $\mathrm{NiO}$ thin film measured in the electrolytes cited previously.

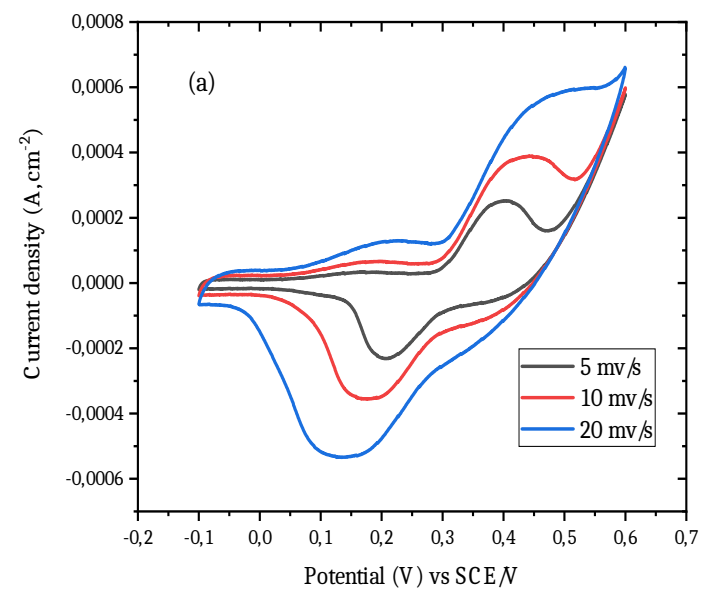

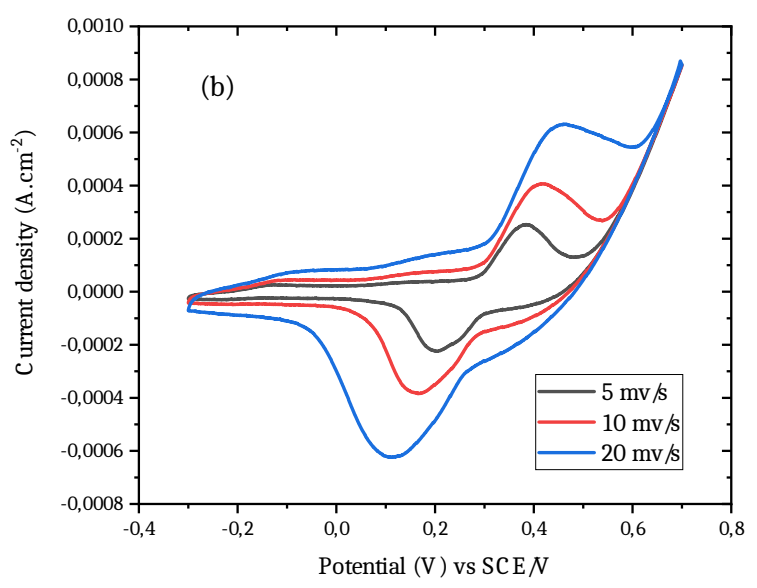

Figure 6. (a) $\mathrm{CV}$ curves of $\mathrm{Pt} / \mathrm{KOH} 1 \mathrm{M} / \mathrm{SCE} / \mathrm{NiO}$ vs $\mathrm{SCE}$ ($0.1 \mathrm{~V}$ to $0.6 \mathrm{~V}$ ), (b) $\mathrm{CV}$ curves of $\mathrm{Pt} / \mathrm{NaOH} 1 \mathrm{M} / \mathrm{SCE} / \mathrm{NiO}$ vs SCE $(-0.3 \mathrm{~V}$ to $0.7 \mathrm{~V})$.

As observed, the shape of all (a) and (b) CV curves are almost the same with two redox peaks. Oxidation peak related to charging process and reduction peak for discharging process [31]. All CV peaks show that the current density increases with an increase in scan rate which proves the direct relationship between CV current and scan rate, suggesting an ideal capacitive characteristic [32]. Also, the small separation between redox peaks suggests a fast electron transfer behavior, which is very important for energy storage systems [31].

Specific capacitance 'Csp' is calculated from the relation [33]:

$$
\mathrm{C}_{\mathrm{sp}}=\frac{1}{\mathrm{mv}\left(\mathrm{V}_{\mathrm{c}}-\mathrm{V}_{\mathrm{a}}\right)} \int_{\mathrm{V}_{\mathrm{a}}}^{\mathrm{V}_{\mathrm{c}}} \mathrm{I}(\mathrm{V}) \mathrm{dV}
$$

where, $\mathrm{v}$ is the potential scan rate $\left(\mathrm{mV} \cdot \mathrm{s}^{-1}\right),(\mathrm{Vc}-\mathrm{Va})$ is a working potential window, (I) is the current response $(\mathrm{mA})$ of the $\mathrm{NiO}$ electrode for the unit area $\left(1 \mathrm{~cm}^{2}\right)$.

From Figure 7. it is observed that the value of specific capacitance decreases with an increase in scan rate for both electrolytes. This may be due to the fact that at a low scan rate there is sufficient time for transfer of charges between electrolyte and electrode interface. Maximum specific capacitance is found to be $24 \mathrm{~F} . \mathrm{g}^{-1}$ at a scan rate of $5 \mathrm{mV} . \mathrm{s}^{-1}$ for $\mathrm{KOH}$ electrolyte. 


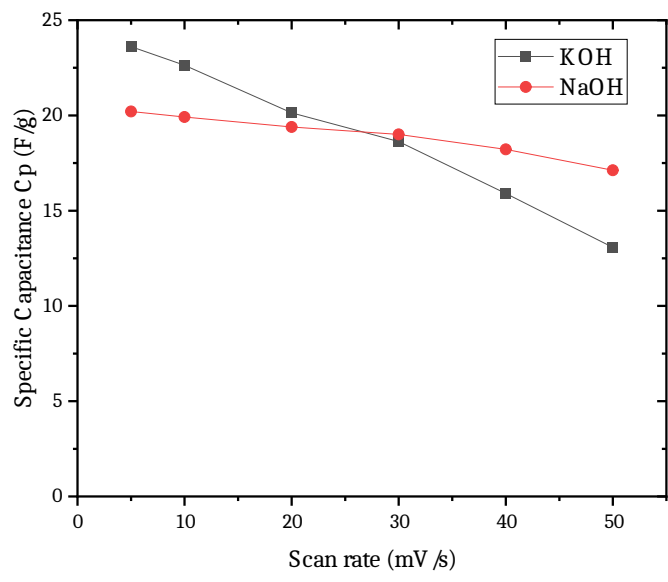

Figure 7. Variation of specific capacitance with scan rate in the $\mathrm{KOH}$ or $\mathrm{NaOH}$ electrolytes.

The general reaction or charge storage for nickel oxide electrode in the $\mathrm{KOH}$ or $\mathrm{NaOH}$ electrolytes is [34], [35]:

$$
\mathrm{NiO}+x \mathrm{OH}^{-} \leftrightarrow x \mathrm{NiOOH}+\mathrm{e}^{-}
$$

Where $x$ represents $\mathrm{K}$ or Na metal elements.

The transition from $\mathrm{NiO}$ to $\mathrm{NiOOH}$ after intercalation of $\mathrm{OH}^{-}$ions provoke charge transfer from $\mathrm{Ni}^{2+}$ to $\mathrm{Ni}^{3+}$. Due to this transfer, the films get colored. During the cathodic scan, the reduction of $\mathrm{Ni}^{3+}$ to $\mathrm{Ni}^{2+}$ causes the bleaching of the film [36].

The transmittance spectra of the $\mathrm{NiO}$ layer in the colored and bleached states were recorded in the wavelength range of 350 to $850 \mathrm{~nm}$, as shown in (Figure 8). The values are obtained after subtracting the transmittance of the ITO substrates using a UV-Vis-NIR spectrometer. This result is further used to calculate the coloration efficiency (CE) using the equation [14]:

$$
\mathrm{CE}_{\lambda=630 \mathrm{~nm}}=\frac{(\Delta \mathrm{OD})_{630 \mathrm{~nm}}}{\mathrm{Q}_{\mathrm{i}}}
$$

where $(\Delta \mathrm{OD})$ is the change in optical density at $\lambda=630$ $\mathrm{nm}$ and $\mathrm{Q}_{\mathrm{i}}$ is the intercalated charge $\left(\mathrm{mC} / \mathrm{cm}^{2}\right)$.

The electrochromic parameters for the sample are given in Table 3. The value of $\mathrm{CE}$ is found to be a maximum of $15,15 \mathrm{~cm}^{2} / \mathrm{C}$ for the electrolyte $\mathrm{KOH}$. These calculated values are relatively low compared to the previous works, this may be due to the smooth morphology of the thin film, which does not allow good intercalation of $\mathrm{OH}^{-}$ions [30].
Table 3. Electrochromic parameters of $\mathrm{NiO}$ film measured in alkaline solutions.

\begin{tabular}{|c|c|c|}
\hline Electrolyte (1M) & $\Delta \mathrm{OD}$ & $\begin{array}{c}\text { Coloration } \\
\text { efficiency } \\
\left(\mathrm{cm}^{2} / \mathrm{C}\right)\end{array}$ \\
\hline $\mathrm{KOH}$ & 0,13 & 15,15 \\
\hline $\mathrm{NaOH}$ & 0,076 & 7,8 \\
\hline
\end{tabular}
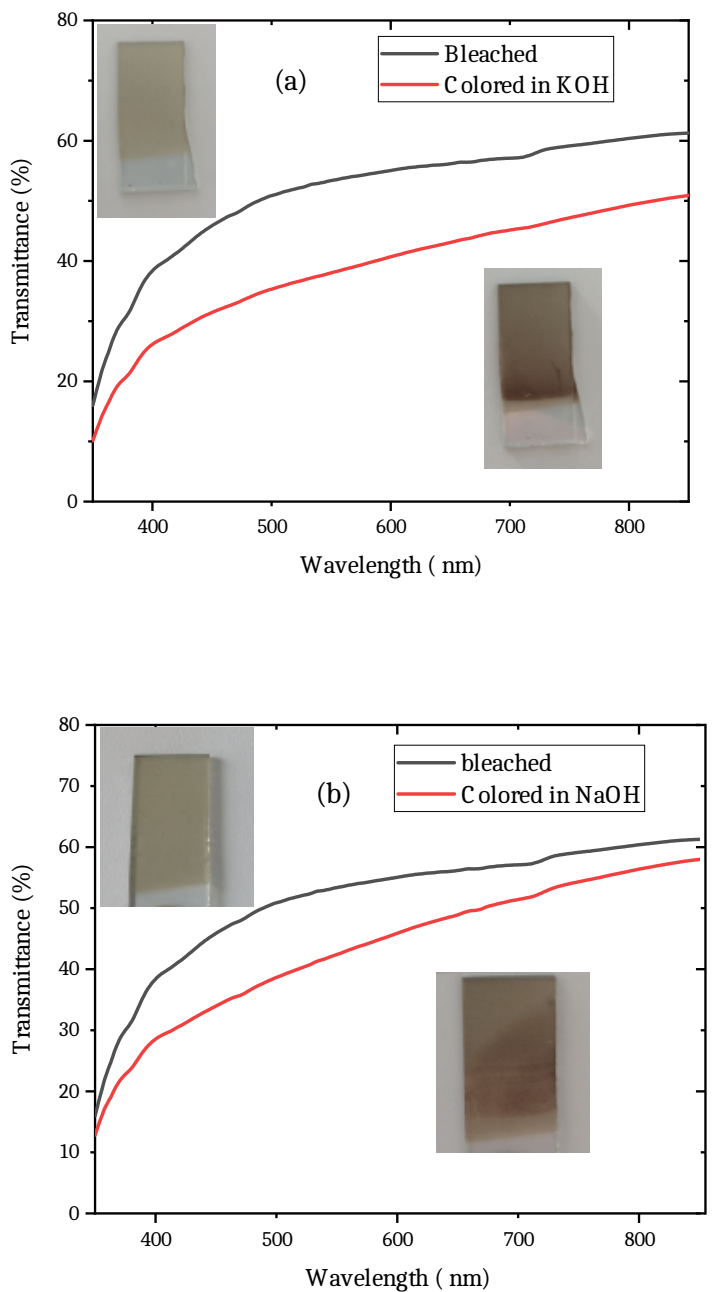

Figure 8. Optical transmittance in colored and bleached state of $\mathrm{NiO}$ thin layer recorded in: (a) $1 \mathrm{M} \mathrm{KOH}$ electrolyte at $(-0,1$ to $0,6 \mathrm{~V}$ vs SCE) (b) $1 \mathrm{M} \mathrm{NaOH}$ electrolyte at $(-0,3$ to $0,7 \mathrm{~V}$ vs SCE).

The stability of the film is one of the important parameters to be taken into account for electrochemical applications [37]. The CV stability of $\mathrm{NiO}$ film has been investigated by recording 50 cycles of the oxydo/reduction operation at a scan rate of $20 \mathrm{mV} / \mathrm{s}$ (Figure 9). From the stability measurements, it is observed that $\mathrm{NiO}$ film is stable in both electrolytes. 

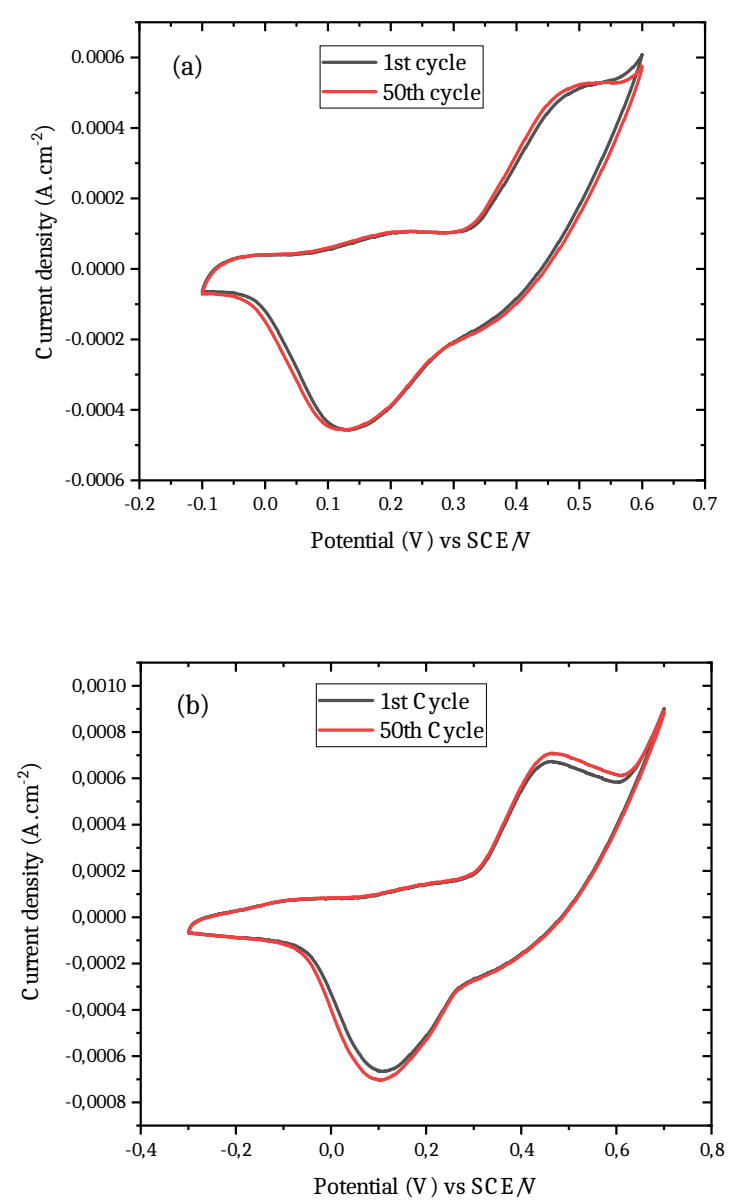

Figure 9. Cyclic voltammograms of $\mathrm{NiO}$ after 50 th cycle at a scan rate of $20 \mathrm{mV} / \mathrm{s}$ in; (a) $1 \mathrm{M} \mathrm{KOH}$ electrolyte (b) $1 \mathrm{M} \mathrm{NaOH}$ electrolyte.

\section{Conclusion}

In this work, Nickel oxide thin film was successfully elaborated using the spray pyrolysis technique on the glass substrate. The structural, morphological, optical, and electrochemical properties were studied using X-ray diffraction, scanning electron microscope, UV-visibleNIR spectroscopy, and cyclic voltammetry techniques. The crystallographic study showed a polycrystalline cubic structure with preferential orientation on the plane (111). Surface morphology revealed a smooth and dense surface. Optical analysis showed an average transmission of about $55 \%$ in visible light range and gives an average direct band gap of $3,71 \mathrm{eV}$. Cyclic voltammograms of the sprayed film presented almost the same curves with two redox peaks. The Specific capacitance and the coloration efficiency of the $\mathrm{NiO}$ layer in $1 \mathrm{M} \mathrm{KOH}$ were $24 \mathrm{Fg}^{-1}$ (at the scan rate of $5 \mathrm{mv} / \mathrm{s}$ ) and $15 \mathrm{~cm}^{2} / \mathrm{C}$ respectively. These values decreased in $1 \mathrm{M} \mathrm{NaOH}$ electrolyte to become 20 $\mathrm{Fg}^{-1}$ and $7,8 \mathrm{~cm}^{2} / \mathrm{C}$, which demonstrates the better performance of $\mathrm{KOH}$ than $\mathrm{NaOH}$ electrolyte. The stability measurement revealed that $\mathrm{NiO}$ film is stable in both electrolytes indicating its capability to insert/extract the ions for many cycles.

\section{References}

[1] R. O. Ijeh et al., "Magnetic and optical properties of electrodeposited nanospherical copper doped nickel oxide thin films," Physica E: Low-dimensional Systems and Nanostructures, vol. 113, pp. 233-239, Sep. 2019, doi: 10.1016/j.physe.2019.05.013.

[2] I. Fasaki, A. Koutoulaki, M. Kompitsas, and C. Charitidis, "Structural, electrical and mechanical properties of $\mathrm{NiO}$ thin films grown by pulsed laser deposition," Applied Surface Science, vol. 257, no. 2, pp. 429-433, Nov. 2010, doi: 10.1016/j.apsusc.2010.07.006.

[3] H. Lee, Y.-T. Huang, M. W. Horn, and S.-P. Feng, "Engineered optical and electrical performance of rfsputtered undoped nickel oxide thin films for inverted perovskite solar cells," Sci Rep, vol. 8, no. 1, p. 5590, Apr. 2018, doi: 10.1038/s41598-018-23907-0.

[4] P. S. Patil and L. D. Kadam, "Preparation and characterization of spray pyrolyzed nickel oxide (NiO) thin films," Applied Surface Science, vol. 199, no. 1, pp. 211-221, Oct. 2002, doi: 10.1016/S0169-4332(02)008395.

[5] Y. Akaltun and T. Çayır, "Fabrication and characterization of $\mathrm{NiO}$ thin films prepared by SILAR method," Journal of Alloys and Compounds, vol. 625, pp. 144-148, Mar. 2015, doi: 10.1016/j.jallcom.2014.10.194.

[6] A. D. Jagadale, V. S. Kumbhar, D. S. Dhawale, and C. D. Lokhande, "Potentiodynamically deposited nickel oxide (NiO) nanoflakes for pseudocapacitors," Journal of Electroanalytical Chemistry, vol. 704, pp. 90-95, Sep. 2013, doi: 10.1016/j.jelechem.2013.06.020.

[7] R. Paulose, R. Mohan, and V. Parihar, "Nanostructured nickel oxide and its electrochemical behaviour-A brief review," Nano-Structures \& NanoObjects, vol. 11, pp. 102-111, Jul. 2017, doi: 10.1016/j.nanoso.2017.07.003.

[8] A. J. Haider, R. Al- Anbari, H. M. Sami, and M. J. Haider, "Photocatalytic Activity of Nickel Oxide," Journal of Materials Research and Technology, vol. 8, no. 3, pp. 2802-2808, May 2019, doi: 10.1016/j.jmrt.2019.02.018.

[9] M. Tyagi, M. Tomar, and V. Gupta, "Optical Properties of NiO Thin Films: A Potential Material for Optoelectronic Devices," Advanced Materials Research, vol. 488-489, pp. 103-108, 2012, doi: 10.4028/www.scientific.net/AMR.488-489.103.

[10] M. Napari et al., "Antiferromagnetism and p-type conductivity of nonstoichiometric nickel oxide thin films," InfoMat, vol. 2, no. 4, pp. 769-774, 2020, doi: 10.1002/inf2.12076.

[11] J. Jung, D. L. Kim, S. H. Oh, and H. J. Kim, "Stability enhancement of organic solar cells with solution-processed nickel oxide thin films as hole transport layers," Solar Energy Materials and Solar Cells, 
vol. 102, pp. 103-108, Jul. 2012, doi: 10.1016/j.solmat.2012.03.018.

[12] A. M. Soleimanpour, A. H. Jayatissa, and G. Sumanasekera, "Surface and gas sensing properties of nanocrystalline nickel oxide thin films," Applied Surface Science, vol. 276, pp. 291-297, Jul. 2013, doi: 10.1016/j.apsusc.2013.03.085.

[13] G. S. Gund, C. D. Lokhande, and H. S. Park, "Controlled synthesis of hierarchical nanoflake structure of $\mathrm{NiO}$ thin film for supercapacitor application," Journal of Alloys and Compounds, vol. 741, pp. 549-556, Apr. 2018, doi: 10.1016/j.jallcom.2018.01.166.

[14] H. Lin et al., "The growth, properties and application of reactively sputtered nickel oxide thin films in all thin film electrochromic devices," Materials Science and Engineering: B, vol. 270, p. 115196, Aug. 2021, doi: 10.1016/j.mseb.2021.115196.

[15] S. J. Lee, T.-G. Lee, S. Nahm, D. H. Kim, D. J. Yang, and S. H. Han, "Investigation of all-solid-state electrochromic devices with durability enhanced tungsten-doped nickel oxide as a counter electrode," Journal of Alloys and Compounds, vol. 815, p. 152399, Jan. 2020, doi: 10.1016/j.jallcom.2019.152399.

[16] H. Yang, J.-H. Yu, H. J. Seo, R. H. Jeong, and J.H. Boo, "Improved electrochromic properties of nanoporous $\mathrm{NiO}$ film by $\mathrm{NiO}$ flake with thickness controlled by aluminum," Applied Surface Science, vol. 461, pp. 88-92, Dec. 2018, doi: 10.1016/j.apsusc.2018.05.231.

[17] A. S. Kondrateva, M. V. Mishin, and S. E. Alexandrov, "TOF MS Investigation of Nickel Oxide CVD," J. Am. Soc. Mass Spectrom., vol. 28, no. 11, pp. 2352-2360, Nov. 2017, doi: 10.1007/s13361-017-1765-1.

[18] M. H. Raza et al., "Tuning the NiO Thin Film Morphology on Carbon Nanotubes by Atomic Layer Deposition for Enzyme-Free Glucose Sensing," ChemElectroChem, vol. 6, no. 2, pp. 383-392, 2019, doi: $10.1002 /$ celc. 201801420 .

[19] P. Salunkhe, M. A. A.V, and D. Kekuda, "Structural, spectroscopic and electrical properties of dc magnetron sputtered $\mathrm{NiO}$ thin films and an insight into different defect states," Appl. Phys. A, vol. 127, no. 5, p. 390, Apr. 2021, doi: 10.1007/s00339-021-04501-0.

[20] M. A. Hameed, O. A. Ali, and S. S. M. Al-Awadi, "Optical properties of Ag-doped nickel oxide thin films prepared by pulsed-laser deposition technique," Optik, vol. 206, p. 164352, Mar. 2020, doi: 10.1016/j.ijleo.2020.164352.

[21] D. R. Sahu, T.-J. Wu, S.-C. Wang, and J.-L. Huang, "Electrochromic behavior of $\mathrm{NiO}$ film prepared by e-beam evaporation," Journal of Science: Advanced Materials and Devices, vol. 2, no. 2, pp. 225-232, Jun. 2017, doi: 10.1016/j.jsamd.2017.05.001.
[22] K. O. Ukoba, A. C. Eloka-Eboka, and F. L. Inambao, "Review of nanostructured $\mathrm{NiO}$ thin film deposition using the spray pyrolysis technique," Renewable and Sustainable Energy Reviews, vol. 82, pp. 2900-2915, Feb. 2018, doi: 10.1016/j.rser.2017.10.041.

[23] S. Zargouni, S. El Whibi, E. Tessarolo, M. Rigon, A. Martucci, and H. Ezzaouia, "Structural properties and defect related luminescence of $\mathrm{Yb}$-doped $\mathrm{NiO}$ sol-gel thin films," Superlattices and Microstructures, vol. 138, p. 106361, Feb. 2020, doi: 10.1016/j.spmi.2019.106361.

[24] J.-H. Yu, S.-H. Nam, Y. E. Gil, and J.-H. Boo, "The effect of ammonia concentration on the microstructure and electrochemical properties of $\mathrm{NiO}$ nanoflakes array prepared by chemical bath deposition," Applied Surface Science, vol. 532, p. 147441, Dec. 2020, doi: 10.1016/j.apsusc.2020.147441.

[25] B. R. Cruz-Ortiz, M. A. Garcia-Lobato, E. R. Larios-Durán, E. M. Múzquiz-Ramos, and J. C. Ballesteros-Pacheco, "Potentiostatic electrodeposition of nanostructured $\mathrm{NiO}$ thin films for their application as electrocatalyst," Journal of Electroanalytical Chemistry, vol. 772, pp. 38-45, Jul. 2016, doi: 10.1016/j.jelechem.2016.04.020.

[26] H. Ftouhi, Z. E. Jouad, M. Jbilou, M. Diani, and M. Addou, 'Study of microstructural, morphological and optical properties of sprayed vanadium doped $\mathrm{ZnO}$ nanoparticles', Eur. Phys. J. Appl. Phys., vol. 87, no. 1, Art. no. 1, Jul. 2019, doi: 10.1051/epjap/2019190111.

[27] P. S. Patil and L. D. Kadam, "Preparation and characterization of spray pyrolyzed nickel oxide $(\mathrm{NiO})$ thin films," Applied Surface Science, vol. 199, no. 1, pp. 211-221, Oct. 2002, doi: 10.1016/S0169-4332(02)008395.

[28] S. A. Hameed, M. M. Kareem, Z. T. Khodair, and I. M. Mohammed Saeed, "The influence of deposition temperatures on the structural and optical properties for $\mathrm{NiO}$ nanostructured thin films prepared via spray pyrolysis technique," Chemical Data Collections, vol. 33, p. 100677, Jun. 2021, doi: 10.1016/j.cdc.2021.100677.

[29] K. S. Usha, R. Sivakumar, C. Sanjeeviraja, V. Sathe, V. Ganesan, and T. Y. Wang, "Improved electrochromic performance of a radio frequency magnetron sputtered $\mathrm{NiO}$ thin film with high optical switching speed," $R S C A d v$., vol. 6, no. 83, pp. 79668 79680, Aug. 2016, doi: 10.1039/C5RA27099E.

[30] X. H. Xia, J. P. Tu, J. Zhang, X. L. Wang, and W. K. Zhang, "Morphology effect on the electrochromic and electrochemical performances of $\mathrm{NiO}$ thin films," Electrochimica Acta, vol. 53, no. 18, pp. 5721-5724, Jul. 2008, doi: 10.1016/j.electacta.2008.03.047.

[31] A. A. Yadav and U. J. Chavan, "Influence of substrate temperature on electrochemical supercapacitive performance of spray deposited nickel oxide thin films," Journal of Electroanalytical Chemistry, vol. 782, pp. 3642, Dec. 2016, doi: 10.1016/j.jelechem.2016.10.006. 
[32] C.-C. Hu and T.-W. Tsou, "Ideal capacitive behavior of hydrous manganese oxide prepared by anodic deposition," Electrochemistry Communications, vol. 4, no. 2, pp. 105-109, Feb. 2002, doi: 10.1016/S13882481(01)00285-5.

[33] A. A. Yadav, "SnO2 thin film electrodes deposited by spray pyrolysis for electrochemical supercapacitor applications," Journal of Materials Science: Materials in Electronics, vol. 27, no. 2, pp. 1866-1872, 2016, doi: 10.1007/s10854-015-3965-4.

[34] S. Vijayakumar, S. Nagamuthu, and G. Muralidharan, "Supercapacitor studies on $\mathrm{NiO}$ nanoflakes synthesized through a microwave route," ACS Applied Materials and Interfaces, vol. 5, no. 6, pp. 2188-2196, 2013, doi: 10.1021/am400012h.

[35] J. Zhao, Y. Tian, A. Liu, L. Song, and Z. Zhao, "The $\mathrm{NiO}$ electrode materials in electrochemical capacitor: A review," Materials Science in Semiconductor Processing, vol. 96, pp. 78-90, Jun. 2019, doi: 10.1016/j.mssp.2019.02.024.

[36] D. Dong et al., "Electrochromic properties of $\mathrm{NiOx}: \mathrm{H}$ films deposited by DC magnetron sputtering for ITO/NiOx:H/ZrO2/WO3/ITO device," Applied Surface Science, vol. 357, pp. 799-805, Dec. 2015, doi: 10.1016/j.apsusc.2015.09.056.

[37] Z. Li et al., "Nickel oxide film with tertiary hierarchical porous structure and high electrochromic performance and stability," Materials Chemistry and Physics, vol. 269, p. 124738, Sep. 2021, doi: 10.1016/j.matchemphys.2021.124738. 